\title{
EVIDENCES FOR STRONG MIXED-POLARITY MAGNETIC FIELDS IN AREA OF A SEISMIC SOURCE ASSOCIATED WITH LARGE PROTON SOLAR FLARE
}

\author{
V.G. Lozitsky ${ }^{1}$, E.A. Baranovsky ${ }^{2}$, N.I. Lozitska ${ }^{1}$ and V.P.Tarashchuk ${ }^{2}$ \\ ${ }^{1}$ Astronomical Observatory of the Taras Shevchenko National University \\ of Kyiv, Kyiv, Ukraine, lozitsky_v@ukr.net,nloz@observ.univ.kiev.ua \\ ${ }^{2}$ Crimea Astrophysical Observatory, Nauchny 98409, Crimea \\ edvard@craocrimea.ru,veratar4@gmail.com
}

\begin{abstract}
We present in a concise statement the new results based on spectral-polarization measurements of magnetic fields in an extremely powerful proton solar flare on October 28, 2003 of X17.2 / 4B class. The observation material was obtained with Echelle spectrograph of HST AO KNU, which makes it possible to analyze the spectral manifestations of the Zeeman effect in very many lines of the visible region of the spectrum, including the photospheric and chromospheric lines. The $I \pm V$ and $V$ profiles of about ten FeI and FeII lines, as well as the $H \alpha, H \beta, H \gamma$, and $H \delta$ lines were studied in a area of the seismic source of the flare, which was localized in the sunspot penumbra of $S$ magnetic polarity. In this flare, we found an unprecedented Balmer decrement of intensities of $\mathrm{H} \alpha$ and $\mathrm{H} \beta$ lines which corresponds to ratio $I(H \beta) / I(H \alpha)=1.68$. In the FeI 5434.5 line with very low Lande factor $\left(g_{\text {eff }}=-0.014\right)$, a reliable splitting of emission peaks was found, which could indicate superstrong magnetic fields (about $50 \mathrm{kG}$ ) of $N$ polarity. Indications for magnetic fields with intensity $\approx 12 \mathrm{kG}$ of $S$ polarity were found too. These indications are based on the study of the Stokes $V$ profile of FeII 5234.6 line. In this line, there were two positive and two negative peaks of profile $V$, indicating a twocomponent structure of the magnetic field. According to the simulation data, the small-scale component with the above-mentioned superstrong magnetic field had a filling factor about 0.1 and had narrow (about twice) the halfwidths of the line profiles. The close contact of subtelescopic magnetic fields of different magnetic polarity, but of lower intensity $(\mathrm{B} \approx 1 \mathrm{kG})$ was also indicated by the comparison of the half-widths of the FeI 5247.1 and 5250.2 lines. In general, it can be concluded that the necessary conditions for the reconnection of magnetic lines were fulfilled even at the photospheric level, rather than in the corona or chromosphere, as suggested by theoretical models of solar flares.
\end{abstract}

Keywords: Sun, solar activity, solar flares, magnetic fields, spectral lines, the Zeeman effect, superstrong magnetic fields, mixed-polarity magnetic fields, sunquakes.
АНОТАЦІ. Ми представляємо у стислому викладі нові результати, які базуються на спектральнополяризаційних вимірюваннях магнітних полів у винятково потужному протонному сонячному спалаху 28 жовтня 2003 р. балу X17.2/4B. Спостережний матеріал був отриманий на ешельному спектрографі ГСТ АО КНУ, завдяки чому є можливість аналізувати спектральні прояви ефекту Зеємана у дуже багатьох лініях видимої області спектру, в тому числі у фотосферних і хромосферних лініях. Було вивчено профілі $I \pm V$ i $V$ близько десяти ліній FeI i FeII, а також ліній $H \alpha, H \beta, H \gamma$ і $H \delta$ в області сейсмічного джерела спалаху, яке локалізувалось в області півтіні сонячної плями $S$ полярності. У цьому спалаху ми виявили безпрецедентний бальмерівський декремент, при якому для інтенсивностей в лініях $H \alpha$ і $H \beta$ спостерігалось відношення $I(H \beta) / I(H \alpha)=1.68$. У лінії FeI 5434.53 дуже низьким фактором Ланде $\left(g_{\text {eff }}=-0.014\right)$ виявлено достовірне розщеплення емісійних піків, яке може вказувати на магнітні поля 50 кГс, що мали $N$ полярність. Були також виявлені вказівки на магнітні поля 3 напруженістю $\approx 12$ кГс, що мали $S$ полярність. Ці вказівки грунтуються на вивчені Стоксового профіля $V$ лінії FeII 5234.6. У цій лінії спостерігались два позитивних і два негативних піки профіля $V$, що вказує на двохкомпонентну структуру магнітного поля. Згідно 3 даними моделювання, маломасштабна компонента 3 вказаним вище надсильним магнітним полем має фактор заповнення 0.1 і звужені у 2 рази профілі спектральних ліній. На тісний контакт субтелескопічних магнітних полів різної магнітної полярності, але меншої напруженості ( $B \sim 1$ кГс) вказує також порівняння півширин ліній FeI 5247.1 і 5250.2 у стоксовому параметрі I. В цілому, можна зробити висновок, що в області сейсмічного джерела спалаху виконувались необхідні умови для магнітного пересполучення силових ліній навіть на фотосферному рівні, а не в короні або хромосфері, як це припускається у теоретичних моделях сонячних спалахів.

Ключові слова: Сонце, сонячна активність, сонячні спалахи, магнітні поля, спектральні лінії, ефект Зеємана, надсильні магнітні поля, магнітні поля змішаної полярності, сонцетрясіння. 


\section{Introduction}

Helioseismic waves (sunquakes) are the least studied phenomenon that accompanies the energy release of solar flares. They are observed in the form of perturbations on the photospheric Dopplerograms of the Sun, which extend concentrically from some source of perturbation. Such waves were observed in $\approx 50 \%$ of solar flares, and some such flares had several such sources (Kosovichev, 2015).

Physically, these are acoustic waves that move not on the surface but in the bowels of the Sun (hence the name seismic). They reflected because of the temperature gradient and reach the surface at higher speeds. The velocity of seismic waves, visible on the surface, increases with the distance from the energy source.

Some their parameters are: typical lifetime is 1-3 min, impulse $\sim 10^{24} \mathrm{~g} \mathrm{~cm} \mathrm{/} \mathrm{s,} \mathrm{source} \mathrm{localization} \mathrm{is} \mathrm{photos}$ phere, $(h \approx 30-100 \mathrm{~km})$. Possible energy sources of sunquakes are electron or/and proton beams or electromagnetic forces.

To elucidate the nature of the sunquakes, detailed observational data on the deep layers of the solar photosphere are needed, including, first of all, magnetic fields as one of the probable sources of energy of sunquakes. It is such data that can be obtained from the Echelle Zeeman spectrograms of solar flares. In this paper, we present preliminary results of an analysis of such spectrograms related to the location of a seismic source in a very powerful proton solar flare.

\section{Observations}

The extremely powerful proton solar flare on October 28, 2003 of X17.2 / 4B class was observed with Echelle spectrograph of the horizontal solar telescope of the Astronomical Observatory of Taras Shevchenko National University of Kyiv (HST AO KNU). This instrument, the observational conditions and some other characteristics of the flare were described in detail by Lozitsky et al. (2018). Here we briefly recall that the main advantage of the instrument is that a very wide range of spectrum, from 4000 to $6600 \AA$, can be observed simultaneously. Also simultaneously the spectra in orthogonal circular polarizations, i.e. combinations of Stokes parameters $I+V$ and $I-V$, are recorded.

According to CORONAS, GOES, INTEGRAL, RHESSI, SOHO and TRACE data, the impulsive phase of the flare was from 11:06 to 11:16 UT and had a linebroadening temperature of a few hundred thousand degrees (Schrijver et al, 2006). From the data of High Energy Neutron Detector (HEND) onboard of the Mars Odyssey Mission it follows that the total energy of nonthermal electrons in the flash phase was from $2 \times 10^{32}$ to 6 $\times 10^{33} \mathrm{erg}$ (Nizamov et al, 2018). It is useful to recall that this flare was studied earlier by many authors, e.g. Kiener et al (2006), Mandrini et al (2006), Kosovichev (2006) and Zharkova \& Zharkov (2007), Lozitsky (2009), etc.

Between 9:33 UT and 11:22 UT, eighteen Zeeman spectrograms of this flare were obtained. The spectrogram for 11:06:30 UT corresponds to the peak phase of the flare, while the spectrogram for 11:14:10 UT corresponds to the post-peak phase. Below, we briefly analyze the observational data for both above-named moments. It should be noted that at the time of maximum (11:06:30 UT), the entrance slit of the Echelle spectrograph was in the immediate vicinity $(\approx 0.2$ degrees $)$ from the seismic source, which was located in the region of the sunspot penumbra of $S$ polar polarity and had coordinates $L=$ 291.00 and $\varphi=-16.64$ (Kosovichev (2006) and Zharkova and Zharkov (2007). At 11:14:10 UT, the entrance slit of the spectrograph was projected exactly on the location of the seismic source.

\section{Profiles of lines and magnetic fields}

According to our observations, the flare under study had an unprecedented Balmer decrement of intensities in $H \alpha$ and $H \beta$ lines, namely $I(H \beta) / I(H \alpha)=1.68$ (Lozitsky et al., 2018). Typically, this ratio is less than unity; only four solar flares were observed, when this ratio was greater than unity. At the maximum of the flare, the emission in the $H \beta$ line exceeded the level of the nearest spectral continuum by about 3.2 times. Strong flare emissions were observed also in D3, D1, D2, MgI 5183.6, 5172.7 and $5167.3 \AA$ lines.

Such well known lines as FeI 5250.2, 6302.5, 5247.1 and 6301.5 had in the flare pure Fraunhofer profiles, without emission peaks at their cores. More strong lines FeI 5233 and 5324.2 $\AA$ had weak and splitted emission peaks. Strong emission peaks were observed in FeI lines of $15^{\text {th }}$ multiplet (Fig. 1).

From Fig. 1 it follows that all three lines have similar character of splitting of emissive peaks in line cores. However, it should be noted that for the lines Fe I 5269.5 and $\mathrm{Fe}$ I 5397.1, the Landé factors are positive and equal to 1.208 and 1.426, respectively (Zemanek and Stefanov, 1976).

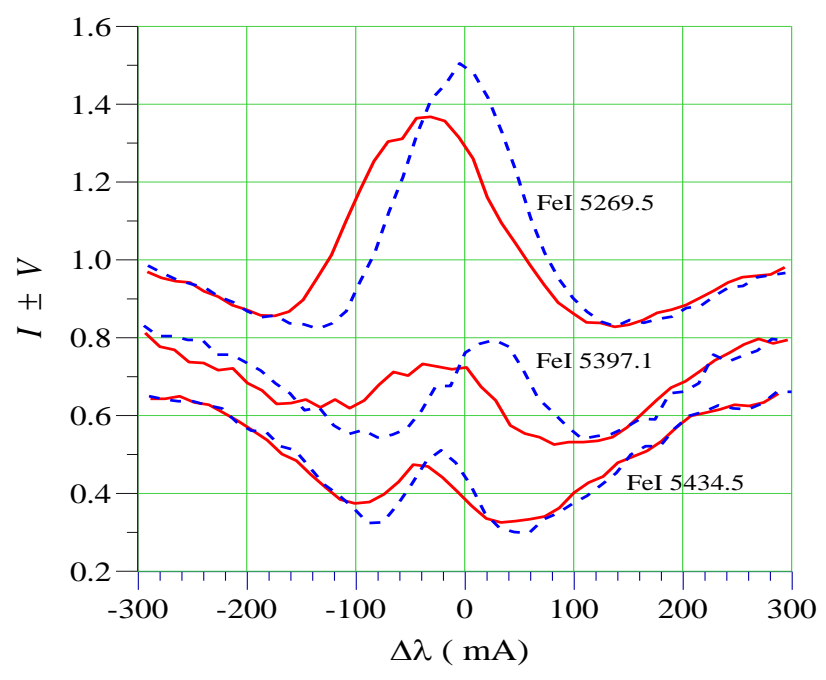

Figure 1: Observed $I \pm V$ profiles of the three FeI lines of $15^{\text {th }}$ multiplet in solar flare of 2003 October 28 for time 11:14 UT (post-peak phase). Position of FeI 5397.1 line is original, whereas other lines are artificially displaced on +0.4 and 0.2 along vertical direction for better comparison. 
Line 5434.5 has a very small and negative Landé factor, namely -0.014 (Landi Degl'Innocenti, 1982). If we take this into account, as well as the actual value of the spectral splitting of the emission peaks in Fig. 1, then we obtain by these lines such magnetic fields: $-1.1,-1.3$ and approximately $+50 \mathrm{kG}$, respectively (the "+" sign corresponds to the $N$ magnetic polarity). Thus, if the splitting of the emission peaks in the core of the 5434.5 line reflects really the Zeeman effect, we have an indication that in the region of the seismic source the magnetic fields differed by more than an order of magnitude and had different magnetic polarity. Such features of the magnetic field are noted inside an area on the Sun having an area of about 3 square mega-meters (Mm), i.e. corresponding to the spatial resolution of our observations.

\section{New data to problem of superstrong fields}

The question of the reality of magnetic fields of a level of $\sim 50 \mathrm{kG}$ is doubtful in connection with the fact that such fields must have a huge magnetic pressure that is 4-9 orders of magnitude higher than the external plasma pressure outside the corresponding structures (Lozitsky, 2015). We can expect that the magnetic field topology in areas of such superstrong fields is extremely peculiar for suppressing such huge difference of pressures even in a short time.

It would seem that to verify the reality of such giant magnetic fields, it is enough to find the corresponding manifestations of the Zeeman effect in lines with large Landé factors. However, the following methodological problems arise here.

(1) Very large Zeeman splittings must correspond to very high magnetic field strengths. For example, for a Fe I 5250.0 line with a Lande factor $\mathrm{g}_{\text {eff }}=3$, the Zeeman splitting should be $1.9 \AA$ if the magnetic field is close to $50 \mathrm{kG}$. But this line has the closest intense spectral blends at distances of $0.4 \AA$ and beyond. It is clear that the corresponding spectral features (i.e. Zeeman's $\sigma$ components) will overlap in the spectrum on blend lines where they are difficult to detect.

(2) There are very few lines of metal in the solar spectrum with simple triplet splitting, which sometimes have emission peaks in solar flares. Namely on such peaks we can measure the magnetic field directly in the region of significant energy release, that is, in the actual solar flare, not under the flare. In the flare studied, such clear emission peaks are observed in the lines of the $15^{\text {th }}$ multiplet of FeI, to which line 5434.5 also belongs. In this multiplet No. 15, the total number of spectral lines is 12 , but only Fe I 5434.5 line is the Zeeman triplet. Its cleavage pattern is very simple: only two single $\sigma$ components with a relative intensity of 0.5 , if we consider the magnetic field to be purely longitudinal (i.e., when the central $\pi$ component is absent). All other lines split anomalously, that is, the intensities of each Zeeman's $\sigma$ component are distributed over some numbers of sub components with intensities of less than 0.5 , which are, in addition, substantially spaced over long distances. As a result, the contrast of the observed pattern of anomalous splitting is significantly reduced for very strong fields and

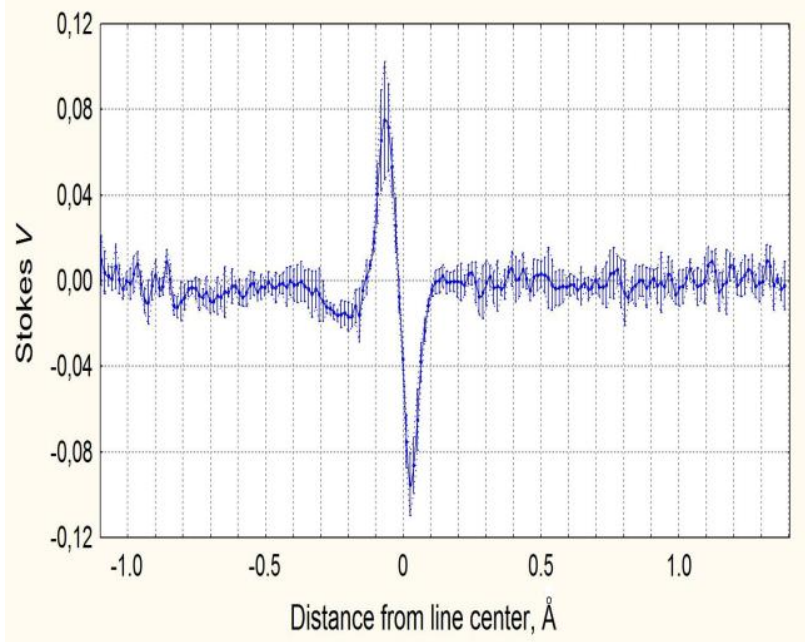

Figure 2: Stokes $V$ profile of Fe I 5371.5 line averaged by five positions in the flare which correspond to about 5 Mm on the Sun.

in the case of photographical observations (as in our case) it could be critically small compared to instrumental noise.

(3) Therefore, the advantage of using lines with very small Lande factors is that they concentrate the spectral contributions from very strong magnetic fields in two narrow intervals of the spectrum placed symmetrically relative to the center of the spectral magnetosensitive line if the relative Doppler velocities are close to zero. Obviously, this is also true for lines with anomalous splitting, because then all sub-components of the Zeeman splitting are concentrated also in virtually the same place in the spectrum.

(4) Spectral lines with very small Lande factors are advantageous for the diagnosis of superstrong magnetic fields also because they give contrasting spectral manifestations even with a large magnetic field dispersion in spatially unresolved structures. Indeed, it would be unrealistic to assume that in such structures the magnetic field is always the same everywhere, that is, the lateral magnetic field profile is rectangular. It is known, for example, that in sunspots this profile is not rectangular but rather smooth, of a Gaussian type. But in a case of insufficient spatial resolution, sections with significantly different magnetic strengths fall simultaneously into the input aperture. Such different strengths correspond to different Zeeman splittings in the spectrum. As a result, the observed sigma components will be very blurred, with weak contrast. This factor, as well as the above factors (1) - (3), make the diagnosis of superstrong fields by lines with large Lande factors very inefficient, with low chances of success.

Considering the remark of an unknown reviewer of our paper for an another journal, we still tried to find signs of the Zeeman effect in line Fe I 5371.493 in the studied flare (Fig. 2).

This line has empirically determined and relatively large Lande factor $\left(g_{\text {eff }}=0.993\right.$ ) which allows to determine the magnetic field more exactly. Due to anomalous Zeeman splitting, each sigma components of this line 
consist by five sub-components which have following splittings in units of normal splitting: 0.738, 0.993, 1.248, 1.503 and 1.758 (Zemanek and Stefanov, 1976). Intensity of this components equal $0.214,0.143,0.086,0.043 \mathrm{i}$ 0.014 , respectively. In case of Zeeman triplet and longitudinal magnetic field, intensity of single sigma component should be 0.5 . This means that the most intensive Zeeman sub-component $(0.738 / 0.214)$ is weaker in comparison with single sigma component of a Zeeman triplet in 2.34 times, in accordance with ratio 0.5/0.214. Obviously, this circumstance makes worse the conditions of observations of the characteristic features in the spectra.

A detailed examination of the observed profiles of $I \pm$ $V$ and $V$ of Fe I 5371.493 line shows that one cannot really conclude that the above features exist. Regarding the Stokes profile $V$ (Fig. 2), we can see something similar at distances of about $-800 \mathrm{~m} \AA$ and $+750 \mathrm{~m} \AA$, but we cannot trace the presence of weaker sub-components. These data relate to the same place in the flare where a clear splitting of emission peaks was observed by FeI 5434.5 line (Fig. 1). Possible reasons for the absence of characteristic spectral manifestations in Fe I 5371.493 line are significant magnetic field dispersion, small filling factor and thermodynamic effects in volumes with very strong magnetic fields.

It can be expected that the influence of the anomalous splitting and magnetic field dispersion will be less for weaker fields. Based on this assumption, profiles of the FeII 5234.6 line were studied in detail. This line has the effective Lande factor 0.869 , its Lande factor for the lower level is 0.980 , and for the upper one is 1.069 , i.e. this line is not a Zeeman triplet (Zemanek and Stefanov, 1985). However, this line has a strong emission in the flare, which completely fills its Fraunhofer profile and reaches a level of 1.3 in units of the continuum level.

It was found for the flare maximum (11:06 UT) that the Stokes parameter $V$ of this line has two positive and two negative peaks (Fig. 3). This can be interpreted as a manifestation of the two-component structure of the magnetic field, in which the weaker secondary peaks belong to the small-scale component with strong fields having a small filling factor. As the simulation showed, in this case, the magnetic field strength in the small-scale component should be about $12 \mathrm{kG}$, and the filling factor of this component is about 0.1. Magnetic polarities in both components is $S$, i.e opposite regarding above-named field of $\sim 50 \mathrm{kG}$. The spectral width of flare emission in strong small-scale component is about 2 times smaller than in a component with a large filling factor. As to magnetic field of $12 \mathrm{kG}$ in the flare, earlier Lozitsky (2015) obtained a similar result using observations in FeI 5233 line.

\section{Semi-empirical model}

For building of a semi-empirical model of photospheric layers of the flare, we used observations of 'non-split' Fe I 5123.7, 5434.5 and 5576.1 $\AA$ lines and a computer program which is an independent implementation of the algorithms in the PANDORA code published by Avrett \& Loeser (1969). This program was created by E.A. Baranovsky (with the help by E. Malanushenko) and it allows to determine the magnetic field and thermodynamical

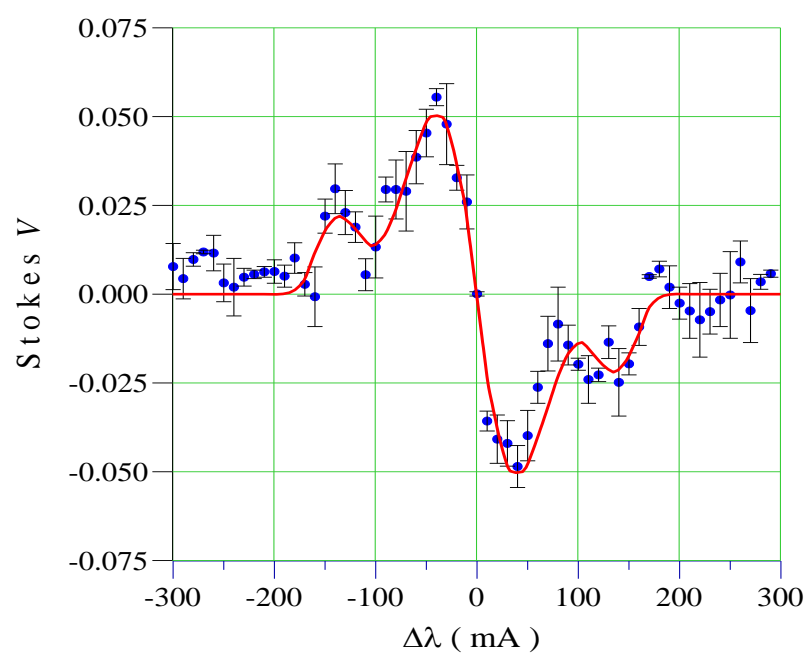

Figure 3: Observed Stokes $V$ profile of FeII 5234.6 line in the flare. Filled circles present observations, solid line data of simulation in frame of two-component model.

conditions on both photospheric and chromospheric levels using non-LTE approximation. In principle, any other program could be used for this purpose, in particular SIR, which allows make the optimal accordance of observations and theory in authomatic regime, on a base of special algorithm. However, it is necessary take into account that SIR has two essential simplifies. Firstly, filling factor in this program is assumed as unchanged with hight in atmosphere. Secondly, simulations for chromospheric layers carry out in LTE approximation. Our experience with programs PANDORA and SIR shown that for photospheric layers both programs give identical results (Andriets et al., 2012).

The semi-empirical model was built by trial and error. A large number of theoretical line profiles were calculated for various distributions with the height of the magnetic field and thermodynamic parameters and such altitude distributions were selected as the most likely that gave the best agreement of the simulations and observations.

In the semi-empirical model, the magnetic field has a remarkable feature, namely, a very narrow and high peak of the magnetic field in the range of $-3.3 \leq \log \tau_{5} \leq-2.5$ (Fig. 4) where $\tau_{5}$ is the optical thickness in the continuum at a wavelength of $\lambda=5000 \AA$. The geometrical thickness of this layer corresponds to $40-50 \mathrm{~km}$. Here, the magnetic field reaches $9 \mathrm{~T}=90 \mathrm{kG}$, which is about 2 times more than according to direct measurements of splitting of emissive peaks in FeI 5434.5 line (see Fig. 1 above).

For $\log \tau_{5} \geq-2.5$, magnetic field is close to zero, which reflects the fact that there is no observed splitting in lines Fe I 5123.7 and Fe I 5576.1, which are formed, in general, lower than the line Fe I 5434.5. As for the temperature in the flare, $T_{\text {flare, }}$ it is increased essentially (by about $500-1500 \mathrm{~K}$ ) for all values of $\log \tau_{5} \leq-0.5$, although the maximum difference between $T_{\text {flare }}$ and $T_{\text {quiet }}$ is observed precisely in the range of the maximum magnetic field. 


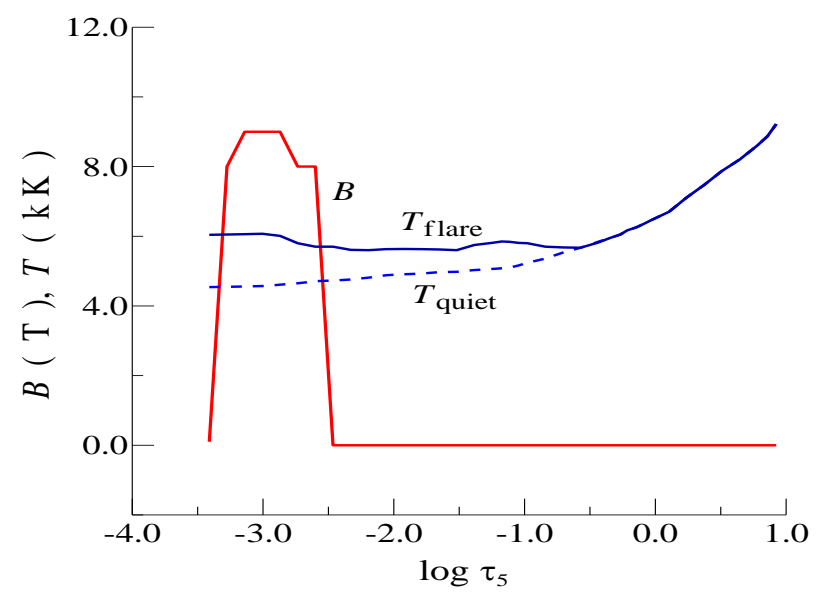

Figure 4: The distribution of the magnetic field $B$ and the temperature $T$ with an optical thickness of $\tau_{5}$ in the flare. For a better comparison of these data, the magnetic field is presented in tesla $(\mathrm{T})$, and the temperature - in kiloquelvines (kK). $T_{\text {flare }}$ and $T_{\text {quiet }}$ are temperatures in the flare and quiet atmosphere.

\section{Conclusion and short discussion}

We found indications for very strong mixed-polarity magnetic fields in an exceptionally powerful solar flare of 2003 October 28 of X17.2 / 4B class. These indications relate to area of the seismic source S2 / S3 according to Kosovichev (2006) and Zharkova and Zharkov ( 2007) in active region NOAA 0486. In this place, Fe I 5434.5 line with very low and empirically determined Lande factor ( $\left.g_{\text {eff }}=-0.014\right)$ has reliable splitting of emissive peaks in $I$ $\pm V$ profiles which can reflect existence of superstrong magnetic field $\left(\sim 10^{4} \mathrm{G}\right)$ of opposite $(N)$ polarity. However, we found no evidence of such very strong fields in another line of the same multiplet of iron, FeI 5371.5, which has $g_{\text {eff }}=0.993$. Perhaps, this discrepancy is caused by the anomalous picture of the Zeeman splitting in second line and magnetic field dispersion in the corresponding spatially unresolved structures. A semiempirical flare model built using the algorithm PANDORA code shows that the extremely strong magnetic fields could be localized in a fairly narrow altitude range (40-50 $\mathrm{km}$ ) of the upper photosphere. Data on other photospheric lines indicate a close proximity of strong magnetic fields of opposite magnetic polarities which could create the necessary conditions for intensive reconnection of lines of force with a powerful energy release in the area of the seismic source.

The present study reveals a significant new feature of the phenomenon of superstrong magnetic fields in flares, namely, their possible concentration in a very narrow altitude range (Fig. 4). That is, the corresponding structures can hardly be imagined as very thin and long magnetic tubes or ropes that stretch from under the photosphere to the temperature minimum zone. Most likely, these are small-scale magnetic balls, whirlwinds, or at least thin magnetic sheets that rise during the flare at speeds of 1-2 $\mathrm{km} \mathrm{s}^{-1}$. The latter, apparently, indicates their origin, i.e. they occur somewhere deep below the photosphere, where the gas and/or dynamic pressure is large enough to concentrate such a strong magnetic field. A theoretical MHD model of a magnetic vortex, in which very strong magnetic fields are possible, was proposed by Solov'ev (2013).

Acknowledgements. The authors are grateful to Prof. Alexander Kosovichev for presentation of scientific materials and useful discussions. Many thanks also to Oleg Lozitsky and Ivan Yakovkin for creating useful computer programs for processing the observational data. This study was funded by the Taras Shevchenko National University of Kyiv, projects Nos. 16БФ023-01 and 16БФ023-03, and by the Crimea Astrophysical Observatory, the project "Physical relationships of solar formations", grant РФФИ № 16-42-910467 p-аэ.

\section{References}

Andriets E.S., Kondrashova N.N., Kurochka E.V., Lozitsky V.G.: 2012, Bull. Crimean Astrophys. Obs., 108, 1.

Avrett E.H., Loeser R.:1969, SAO, Special Report 303.

Kiener J.,Gros, M., Tatischeff, V.,Weidenspointner, G.: 2006, A\&A, 445, 725.

Kosovichev A. G.: 2006, Solar Phys., 238, 1.

Kosovichev A.: 2015, Sunquakes: Helioseismic response to solar flares, in: V. Tong \& R. García (Eds.),

Extraterrestrial Seismology (pp. 306-322), Cambridge:

Cambridge University Press, doi:10.1017/CBO9781107300668.025.

Landi Degl'Innocenti E.L.: 1982, Solar Phys., 77, 285.

Lozitsky V.G.: 2009, Astron. Letter, 35, 136.

Lozitsky V.G.: 2015, Adv. Space Res., 55, 958.

Lozitsky V.G., Baranovsky E.A., Lozitska N.I. et al.: 2018, MNRAS, 477, 2796.

Mandrini C. H., Demoulin P., Schmieder B., Deluca E. E., Pariat E., Uddin, W.: 2006, Solar Phys., 238, 293.

Nizamov, B. A.; Zimovets, I. V.; Golovin, D. V.et al.: 2018; Journal of Atmospheric and Solar-Terrestrial Physics, 179, 484.

Schrijver, C. J., Hudson,H. S, Murphy,R. J. et al.: 2006, Ap J, 650:1184Y1192

Solov'ev, A.A.: 2013, Solar Phys., 286, 441.

Zemanek E.N., Stefanov A.P., 1976, Vestnik Kiev Univ., Ser. Astronomii, 18, 20.

Zemanek E.N., Stefanov A.P.: 1985, Vestnik Kiev Univ., Astronomiya, 27, 32.

Zharkova V.V., Zharkov S.I., 2007, Ap J, 664, 573. 